\section{UF Savanna Cultivar Group-Eight Colors of Heat-tolerant Lisianthus for Potted Plants}

\author{
Brent K. Harbaugh and Zhanao Deng \\ University of Florida, Institute of Food and Agricultural Sciences, Environmental \\ Horticulture Department, Gulf Coast Research and Education Center, 14625 \\ CR 672, Wimauma, FL 33598
} Additional index words. high temperature, rosette, potted flowering plants, Eustoma
grandiflorum, Gentianaceae, plant breeding

A lisianthus [Eustoma grandiflorum (Raf.) Shinners; Gentianaceae Juss.] breeding program was initiated in 1985 at the University of Florida's Gulf Coast Research and Education Center, Bradenton. The emphasis was on development of pot or bedding plant types with heat-tolerance and and basal branching pot and bedding plant types. Cultivars differ significantly in their sensitivity to high temperatures (Fukuda et al., 1994; Harbaugh et al., 1992; Li et al., 2002). Seedlings of most commercial lisianthus cultivars form rosettes (formation of a basal cluster of leaves with no flowering stems) when grown at or above 25 to $28^{\circ} \mathrm{C}$ (Harbaugh et al., 1992; Harbaugh, 1995; Ohkawa et al., 1991; Ohkawa et al., 1994; Pergola, 1992). 'Maurine Blue'(Harbaugh and Scott, 1996) and 'Florida Blue' (Harbaugh et al., 1996) were the first heat-tolerant lisianthus whose seedlings could be grown at $28 \mathrm{t} 31^{\circ} \mathrm{C}$ without rosetting.

Maurine Blue' was intended to be used as a flowering potted plant when grown with the use of growth retardants or as a bouquet cutflower without growth retardants. Additional colors have been added over the years that also were heat-tolerant with vegetative and flower characteristics similar to 'Maurine Blue'. The Maurine cultivar group now includes pink, pink-lilac, white, light blue, lilac (Harbaugh and Scott, 1998), blue/white (Harbaugh and Scott, 2003), and pink/white (Harbaugh and Scott, 2005 a) bicolored flower colors. When grown without growth retardants, these cultivars have a height suitable for the bouquet cut-flower market.

'Florida Blue' was semi-dwarfand intended to be used as a bedding plant. Additional colors added to form the Florida cultivar group included light blue, pink (Harbaugh and Scott, 1999), silver (Harbaugh and Scott, 2001), blue/white and pink/white (Harbaugh and Scott, 2005 b) bicolored flower colors.

The UF Savanna cultivar group is heattolerant and intermediate in height between the Florida cultivar group and the Maurine cultivar group. The UF Savanna cultivar group

Received for publication 6 Dec. 2005. Accepted for publication 5 Jan. 2006. This research was supported by the Florida Agricultural Expt. Station. We thank Nancy West and Gail Bowman for their excellent technical support. frost, and pink frost (Fig. 1). To our knowlheat-tolerant lisianthus. edge, 'Savanna Blue Frost' and 'Savanna Pink Frost' flower colors are not available in other commercial pot type lisianthus.

\section{Origin}

'UF Savanna Blue' is an $\mathrm{F}_{1}$ hybrid resulting from crossing inbred lines UF03-1240 and UF00-770A (Fig. 2). UF03-1240 was chosen for its large pink flowers, intermediate plant height, sturdy branches and heat-tolerance. UF00-770A was selected for its bright blue flowers and semi-dwarf height.

UF03-1240 was the $F_{7}$ selection of a cross between UF96-404 and a selection of 'Mariachi Double Pink'. A plant with large pink single flowers was selected in the $\mathrm{F}_{2}$ and inbred seven generations selecting for shorter plants and heat-tolerance. UF96-404 was a semi-dwarf selection of UF95-321 (Harbaugh and Scott, 1999) chosen for its bright pink flowers and
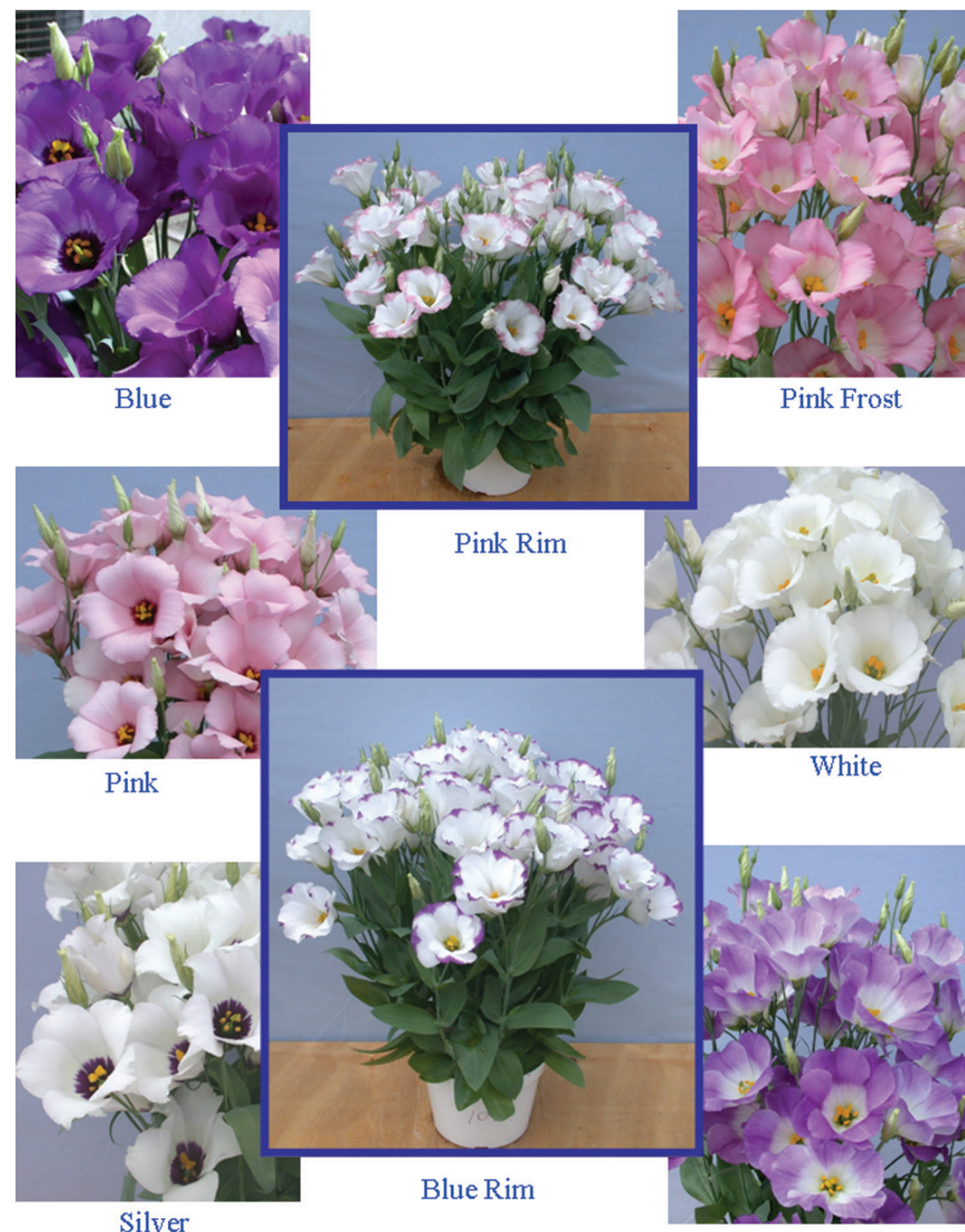

Blue Frost

Fig. 1. 'UF Savanna Blue', 'UF Savanna Pink Frost', 'UF Savanna Pink', 'UF Savanna White', 'UF Savanna Silver', 'UF Savanna Blue Frost', 'UF Savanna Pink Rim', and 'UF Savanna Blue Rim' 
basal branching. A short plant from a population of 'Mariachi Double Pink' was selected for its flower form.

UF00-770A was a selection of UF94-393 (Harbaugh and Scott, 2005 b) and advanced three generations. UF94-393 has a blue rim bicolored flower but a solid blue was found in a large population of plants.

'UF Savanna Pink' is an $\mathrm{F}_{1}$ hybrid resulting from crossing inbred lines UF03-1238 and UF00-792A (Fig. 2). UF03-1238 was used for its large dark pink flowers and intermediate plant height. UF00-792A was used for a source for basal branching. Both selections had excellent heat-tolerance.

UF03-1238 was the $\mathrm{F}_{7}$ of a cross between a selection of 'Double Echo Pink Picotee' and UF97-185. A plant with large pink single flowers was selected in the $\mathrm{F}_{2}$ and inbred five generations selecting for shorter plants and heat tolerance. A plant from a population of 'Double Echo Pink Picotee' was selected for its flower form and dark pink petal color. UF97-185 was selected for its dwarf, basal branching habit. It was the S2 of UF95-321 (see 'UF Savanna Blue').

UF00-792A was the $F_{7}$ of UF94-34 and 'Mermaid Pink'. A dwarf plant with pink flowers was selected in the $\mathrm{F}_{2}$ and advanced five generations for improved pink flower color. UF94-34 (Harbaugh and Scott, 1996) was a blue flowering breeding line but was used as a source of heat-tolerance and basal branching. 'Mermaid Pink' was used for its dwarf plant habit and pink flowers.

'UF Savanna White' is an $\mathrm{F}_{1}$ hybrid resulting from crossing inbred lines UF03-1219 and UF00-878 (Fig. 2). UF03-1219 was chosen for its large white flowers with a green eyespot and intermediate plant height. UF00-878 was used as a source of basal branching and heat-tolerance.

UF03-1219 was the $\mathrm{F}_{5}$ selection of a cross between UF99-712 and UF99-533. Aplant with large white single flowers was selected in the $\mathrm{F}_{2}$ and inbred three generations selecting for pure white flowers with a green eyespot. UF99-712 was the $F_{2}$ selection from UF96163 and 'Mermaid White'. UF99712 was a short, basal branching plant. UF94-163 (Harbaugh and Scott, 1998) was tall and had a blue eyespot. It was crossed with 'Mermaid White' to reduce plant height and develop flowers with a green eyespot.

UF99-533 was the $\mathrm{F}_{2}$ of a cross

Fig.2. Pedigrees of 'UF Savanna Blue', 'UF Savanna Pink', 'UF Savanna White', and 'UF Savanna Silver' $\mathrm{F}_{1}$ heat-tolerant lisianthus. with 'Double Echo Blue Picotee' and UF97-197 chosen for its intermediate height and sturdy stems. A white flowering plant was found in a population of 'Double Echo Blue Picotee' and used for its flower form and pure white flower color. UF97-197 was the S3 selection from UF94-46 (Harbaugh and Scott, 1996) that was used for a source of heat-tolerance.

UF00-878 was the S4 of UF96-426 (Harbaugh and Scott, 2005 b) selected for its pure white flowers and improved four generations selecting for heat-tolerance, basal branching, and sturdy stems.

'UF Savanna Silver' is an $\mathrm{F}_{1}$ hybrid resulting from crossing inbred lines UF99-825 and UF99-831 (Fig. 2). Both parents were selected for their silver flowers and dark blue eyespot. UF99-825 was used because of its huge flowers and intermediate plant height. UF99-831 was shorter but with better basal branching and the flowers had a darker silver color than UF99-825.

UF99-825 was the $\mathrm{F}_{7}$ selection of a cross between UF94-404 and UF94-34. UF94-404 (Harbaugh and Scott, 2001) was a very short plant with white flowers/blue eyespot. UF9434 (see 'UF Savanna Pink') was blue but had excellent heat tolerance. Since blue is dominant over white, a plant with large white flowers was selected in the $\mathrm{F}_{2}$ and inbred five generations selecting for taller plants and a blue eyespot.

UF99-831 was the $\mathrm{F}_{7}$ selection of a cross between UF94-404 and UF94-46. UF94-46

'UF Savanna
Blue'
F1
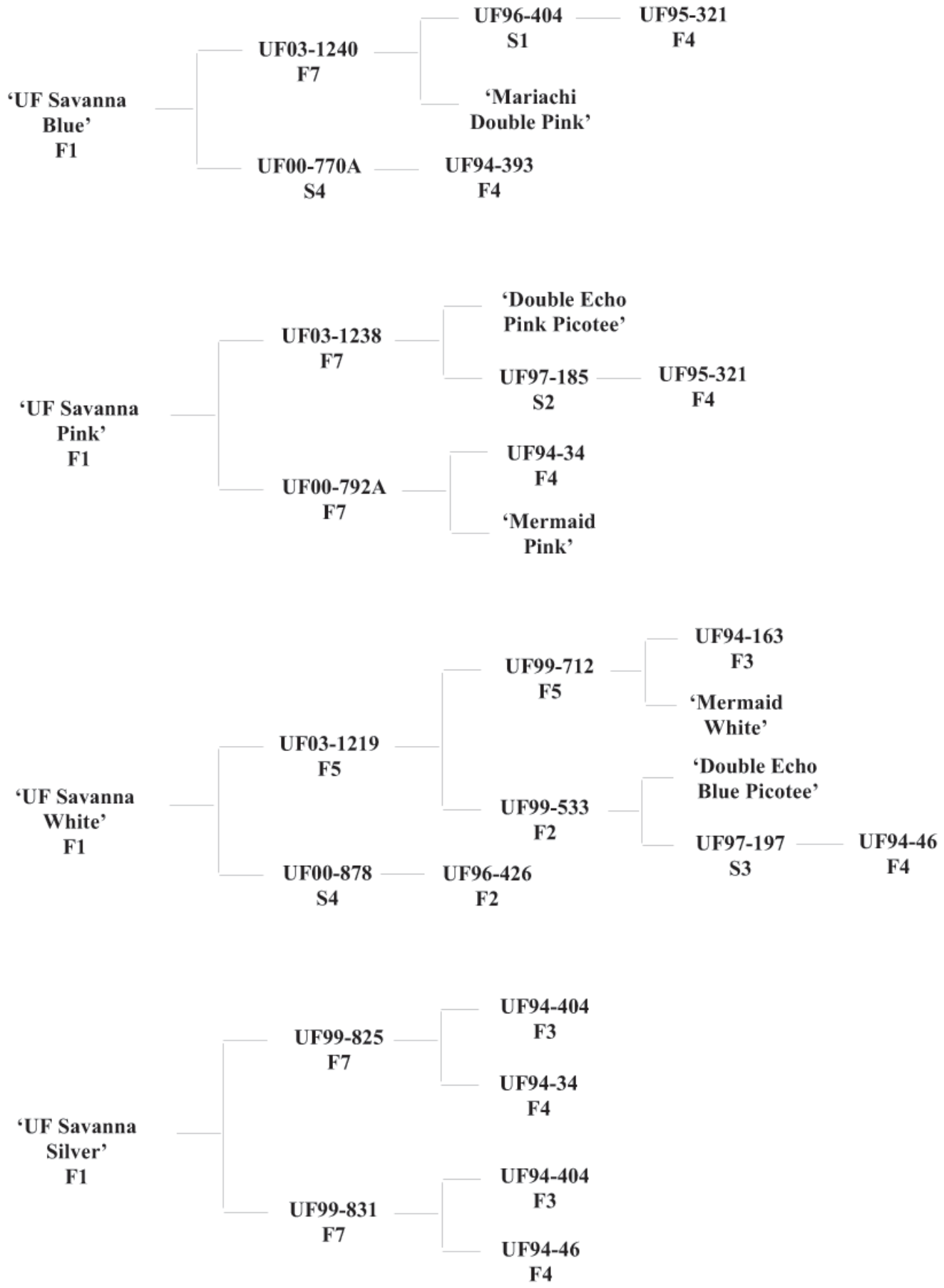
(see 'UF Savanna White') was blue but had excellent heat tolerance and basal branching. A plant with silver flowers was selected in the $F_{2}$ and inbred five generations to stabilize the silver color.

'UF Savanna Blue Rim' is an $\mathrm{F}_{1}$ hybrid resulting from crossing inbred lines UF031351 and UF03-1225 (Fig. 3). UF03-1351 had excellent basal branching and ideal plant height for the UF Savanna cultivar group. UF03-1225 had strong stems. Both selections had flowers with very stable blue rims. Bicolored flowers cam be problematic since the rim color often has undesirable bleeding of blue or pink color downward into the white portion of the petal, a mix of solid-colored and bicolored flowers develop on the same plant or plants within the same population, or the thickness and length of the pink border may vary from just a small blotch to the entire petal apex.

UF03-1351 was the $F_{3}$ selection of a cross between UF00-748 and UF00-625. UF00-748 was the $F_{2}$ of a cross between two dwarf blue rim flowers, 96-255 and UF 96-426, both described in Harbaugh and Scott, (2005b). Although UF00-625 had flowers with a pink

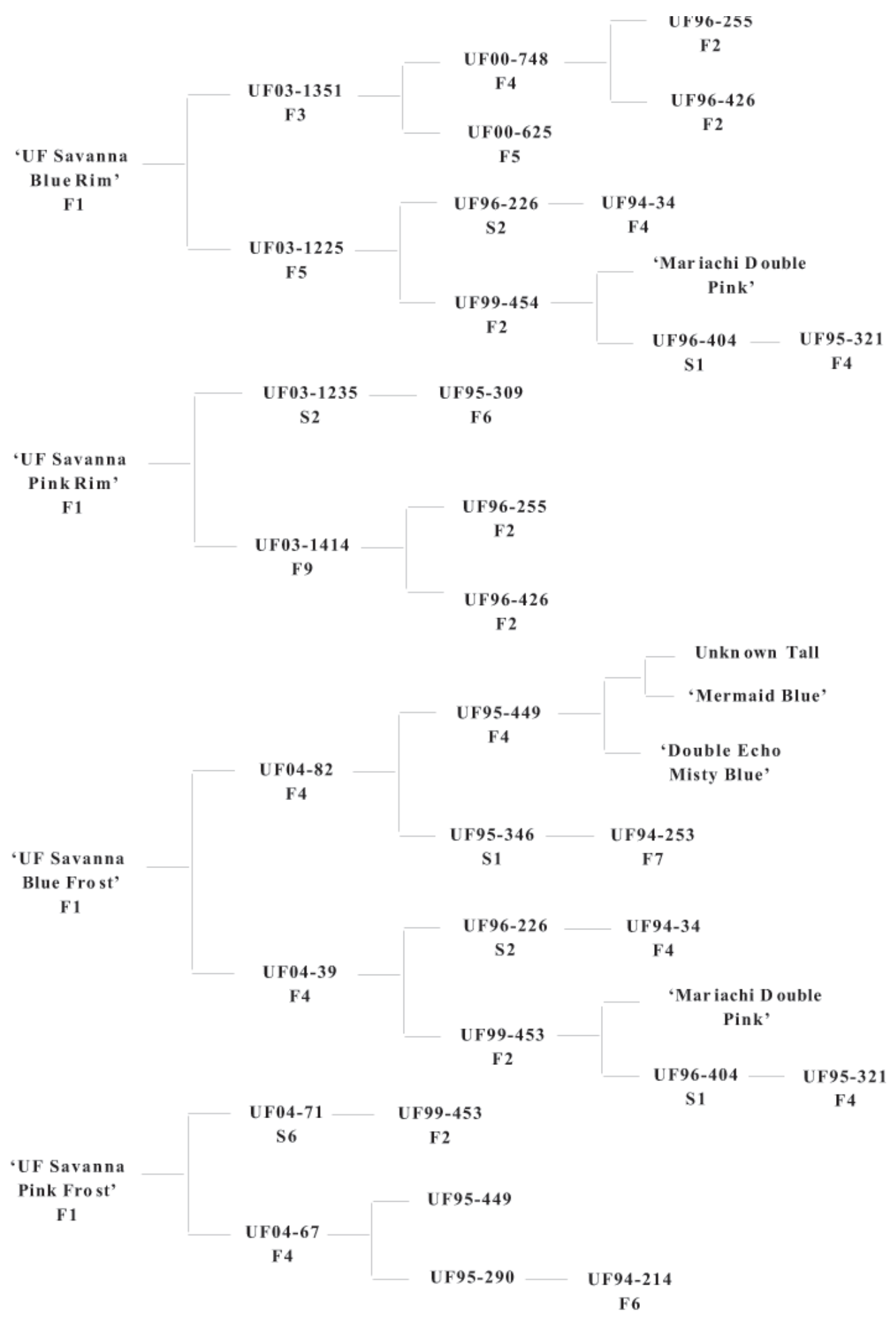

rim, it was used because of its intermediate height and its pure white color and strong thick rim color. Pink and blue rim flowers sorted out in the $\mathrm{F}_{2}$ and a blue rim selection advanced to the $\mathrm{F} 3$.

UF03-1225 was the $\mathrm{F}_{5}$ of a cross between UF96-226 and UF99-454. UF96-226 was the S2 of UF94-34, used as a source of heat tolerance. UF99-454 was the $\mathrm{F}_{2}$ of 'Mariachi Double Pink' and 96-404, the improved $\mathrm{S}_{1}$ of UF95-321 (see 'UF Savanna Blue'). 'Mariachi Double Pink' normally has pink flowers, but a misty pink variant was selected resulting in some bicolored flowers observed in the $\mathrm{F}_{1}$. A selection was made and advanced to the $\mathrm{S}_{1}$.

'UF Savanna Pink Rim' is an $\mathrm{F}_{1}$ hybrid resulting from crossing inbred lines UF03-1235 and UF031414 (Fig. 3). UF03-1235 was chosen for its large pink flowers, dwarf habit, and heat-tolerance. UF03-1414 was selected for its bright pink rim flowers and intermediate height.

UF03-1235 was the S2 of UF95-309 (Harbaugh and Scott, 1999). A plant with a large and very dark pink flower with improved plant size was selected and advanced for improved vigor. UF03-1414 was the F9 of UF96255 and UF96-426 (Harbaugh and Scott, 2001b).

'UF Savanna Blue Frost' is an $\mathrm{F}$ hybrid resulting from crossing inbred lines UF04-82 and UF04-39 (Fig. 3). UF04-82 was chosen for its intermediate plant size and large flowers. UF04-39 was selected for basal branching, dwarf habit, and heat-tolerance. Both parents had flowers with a stable "frost" pattern. This color pattern is unstable and very problematic with many variations in color patterns that can arise.

UF04-82 was the $\mathrm{F}_{4}$ of a cross between UF95-449 and UF95-346. UF95-449 was the F from a cross of an unknown tall plant and 'Mermaid Blue' with 'Double Echo Misty Blue', the original source of the frost pattern. UF95-346 was the $\mathrm{S}_{1}$ of UF94-253 (Harbaugh and Scott, 1998).

UF04-39 was the $\mathrm{F}_{4}$ of a cross between UF96-226 and UF-453. UF96-226, which was an improved line of UF94-34 (see 'UF Savanna Pink') that was selected for heat-tolerance and floriferousness. UF99-453 was the $F_{2}$ of a cross between a misty pink variant of 'Mariachi Double Pink' and

Fig. 3. Pedigrees of 'UF Savanna Blue Rim', 'UF Savanna Pink Rim', 'UF Savanna Blue Frost', and 'UF Savanna Pink Frost' $F_{1}$ heat-tolerant lisianthus. 
Table 1. Percentage rosetted plants ${ }^{\mathrm{z}}$ and growth and flowering characteristics ${ }^{\mathrm{y}}$ of 21 cultivars of lisianthus grown in 11.5 -cm square pots at Bradenton, Fla.

\begin{tabular}{|c|c|c|c|c|c|c|c|}
\hline Cultivar & $\begin{array}{c}\text { Rosetted } \\
(\%)\end{array}$ & $\begin{array}{c}\text { Plant }^{\mathrm{x}} \\
\text { ht } \\
(\mathrm{cm})\end{array}$ & $\begin{array}{l}\text { width } \\
(\mathrm{cm})\end{array}$ & $\begin{array}{c}\text { Branches }^{\mathrm{w}} \\
\text { (no.) }\end{array}$ & $\begin{array}{c}\text { Flowers } \\
\text { and buds } \\
\text { (no.) }\end{array}$ & $\begin{array}{c}\text { Petal } \\
\text { length } \\
(\mathrm{cm})\end{array}$ & $\begin{array}{c}\text { Days to } \\
\text { flower } \\
\text { (no.) }\end{array}$ \\
\hline Florida Blue & 0 & 36 & 21 & 9 & 63 & 6.3 & 115 \\
\hline Forever Blue & 47 & 32 & 25 & 14 & 62 & 5.1 & 109 \\
\hline Lisa Blue & 30 & 23 & 15 & 7 & 33 & 5.0 & 108 \\
\hline Lizzy Blue & 100 & 28 & 17 & 7 & 49 & 5.9 & 116 \\
\hline Mermaid Blue & 40 & 24 & 18 & 10 & 59 & 5.6 & 112 \\
\hline Sapphire Blue & 86 & 25 & 23 & 11 & 49 & 5.6 & 107 \\
\hline Tiramisu Purple & 67 & 37 & 23 & 14 & 70 & 4.9 & 111 \\
\hline UF Savanna Blue & 0 & 40 & 24 & 10 & 75 & 7.2 & 113 \\
\hline UF Savanna Blue Frost & 0 & 45 & 22 & 12 & 75 & 6.3 & 114 \\
\hline UF Savanna Blue Rim & 0 & 40 & 18 & 9 & 47 & 6.1 & 113 \\
\hline UF Savanna Pink & 0 & 38 & 20 & 8 & 60 & 6.0 & 108 \\
\hline UF Savanna Pink Frost & 0 & 47 & 22 & 8 & 69 & 6.3 & 113 \\
\hline UF Savanna Pink Rim & 0 & 43 & 18 & 7 & 59 & 6.1 & 116 \\
\hline UF Savanna Silver & 0 & 41 & 22 & 10 & 65 & 6.7 & 114 \\
\hline UF Savanna White & 0 & 48 & 19 & 9 & 58 & 6.6 & 111 \\
\hline $\operatorname{LSD}(\%=0.05)$ & 25 & 4.6 & 3.0 & 2.2 & 11.6 & 0.4 & 1.7 \\
\hline
\end{tabular}

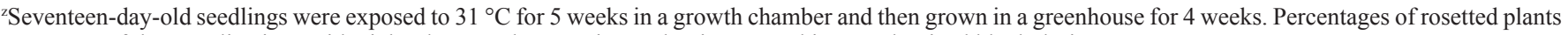
are means of three replications with eight plants as the experimental unit arranged in a randomized block design.

${ }^{y}$ Vegetative and flowering characteristics were for plants grown in a greenhouse at 33 to $35^{\circ} \mathrm{C}$ day and 13 to $15^{\circ} \mathrm{C}$ night. Values are means of five replications of single-plant experimental units arranged in a completely randomized design.

xlant height $=$ distance from the pot rim to the tip of the highest bud measured after three flowers had opened.

wLateral stems forming on the central stem from the basal leaves to the first flower.

UF95-321 (see 'UF Savanna Pink') which was sorting for solid pink and the frost pattern.

'UF Savanna Pink Frost' is an F hybrid resulting from crossing inbred lines UF04-71 and UF04-67 (Fig. 3). UF04-71 was the S6 of UF 99-453 (see 'UF Savanna Blue Frost') that had excellent plant height and flower color for the UF Savanna Series. UF04-67 was the $\mathrm{F}_{4}$ of a cross between UF95-449 (see 'UF Savanna Blue Frost') and UF95-290. A plant with intermediate height and dark pink flower was selected from UF94-214 (Harbaugh and Scott, 1998). It also was an excellent source of stem strength and heat-tolerance.

Growing conditions used to select seedlings for resistance to heat-induced rosetting during development of heat tolerant parents included 1) production during summer months under greenhouse conditions at day temperatures $\geq 35$ ${ }^{\circ} \mathrm{C}, 2$ ) exposure of 2- to 4-week-old seedlings to $28{ }^{\circ} \mathrm{C}$ for 4 weeks in a growth chamber for initial selections in early generations, and 3 ) exposure of 17 -d-old seedlings to $31{ }^{\circ} \mathrm{C}$ in a growth chamber for 5 weeks for selection of final parents used in $\mathrm{F}_{1}$ hybrids. The photosynthetic photon flux in growth chambers was $150-190 \mu \mathrm{mol} \cdot \mathrm{m}^{-2} \cdot \mathrm{s}^{-1}$ from cool-white fluorescent bulbs.

\section{Flower Color Description}

Flower color was determined under natural light using the Royal Horticultural Society Colour Chart (Royal Horticultural Society, 1966). A number plus a letter are used for each color chip (e.g., 155D). Petals of lisianthus typically are one color over most of the surface, but exhibit a distinct basal eyespot (i.e., base of petals surrounding the ovary) of a different color.

'UF Savanna Blue' flower petals are a violet blue (90C) on the adaxial petal surface, diffusing to a variegated 1.6 - to $2.0-\mathrm{cm}$ white $(155 \mathrm{C})$ band at the base of the petals. As the flower matures, the petal color darkens to dark purple (79A) and the white band fades or completely disappears. The abaxial petal surface is a lighter violet (90D) and then darkens to purple (86B) as the flower matures.

'UF Savanna Pink' petals are light pink (65B) on the adaxial surface. The abaxial surface is lighter pink (65D).

'UF Savanna Silver' flower petals are white (155C) on the adaxial and abaxial petal surface. Under certain light conditions, the petals have a blue overtone, thus the name silver rather than white. The eyespot is a violet-blue (83B) and also unique to silver flowers.

'UF Savanna White' flower petals are white (155D) on the adaxial and abaxial petal surfaces. The eyespot is a yellow-green (145B) on both cultivars.

'UF Savanna Blue Rim' and 'UF Savanna Pink Rim' flower petals are predominantly white (155D) on the adaxial and abaxial petal surface. 'UF Savanna Blue Rim' flowers have a violet-blue (89C on the adaxial and lighter violet blue (90C) on the abaxial petal surface) border on the petal apex that is usually 0.5 to $0.75 \mathrm{~cm}$ wide. 'UF Savanna Pink Rim' flowers have a dark pink (55C on the adaxial and $56 \mathrm{~A}$ on the abaxial petal surface) border on the petal apex. The eyespot is a yellow-green (145B) on all four cultivars.

'UF Savanna Blue Frost' flower petals have violet $(86 \mathrm{~B}, \mathrm{C})$ speckles on a white $(155 \mathrm{D})$ background on the abaxial and adaxial petal surfaces. 'UF Savanna Pink Frost' has red purple $(70 \mathrm{C}, \mathrm{D})$ speckles. The speckles on both cultivars are concentrated in a band of about $1.5 \mathrm{~cm}$ at the petal apex giving the appearance of a bicolored flower when viewed from a distance. Both cultivars have a yellow green (150C) eyespot.

\section{Characteristics and Use}

Heat tolerance as well as vegetative and flower characteristics of the UF Savanna cultivar group were compared to seven commercial bedding or pot type cultivars. Seeds of all cultivars were planted on 19 Jan. 2005, at
Bradenton, Fla. Seventeen-day-old seedlings were grown either in a glasshouse (control) with a high of 30 to $33{ }^{\circ} \mathrm{C}$ day and 13 to 15 ${ }^{\circ} \mathrm{C}$ night or at a constant $31{ }^{\circ} \mathrm{C}$ for 5 weeks in a growth chamber (heat-stressed). Seedlings exposed to $31^{\circ} \mathrm{C}$ were rated as rosetted if they had not bolted after growth for an additional 4 weeks in the control greenhouse. Nonrosetted plants from the control greenhouse were evaluated for plant height, plant width, number of branches (lateral stems forming on the central stem from the basal leaves to the first flower), total number of flowers and buds per plant after three flowers were open, petal length, and the number of days from sowing to flowering.

The most important and distinguishing attribute of all the UF Savanna cultivar-group cultivars as compared with other commercial lines was their heat tolerance (Table 1). 'Florida Blue' was an exception but it was released from our program as a semi-dwarf and heat-tolerant line and is now commercialized (Harbaugh et al., 1996). None of the heat stressed Savanna cultivar group rosetted while $47 \%$ 'Forever Blue', 30\% 'Lisa Blue', 100\% 'Lizzy Blue', 40\% 'Mermaid Blue', 86\% ‘Sapphire Blue', and $67 \%$ Tiramisu Purple' seedlings rosetted.

In addition to heat tolerance, we considered that the UF Savanna cultivars exhibited sufficient similarities in flower form and display, branching habit, and in the number of days from sowing to flowering to be included in the UF Savanna cultivar group. Notable differences were that days to flower ranged from 111 to 116 days for all UF Savanna cultivars except 'UF Savanna Pink' that flowered earliest at 108 days, 'UF Savanna Blue Frost' were very floriferous (75 flowers and buds), and 'UF Savanna Blue', 'UF Savanna Silver' and 'UF Savanna White' had very large petals $(7.2,6.7$, and $6.6 \mathrm{~cm}$, respectively).

UF Savanna cultivars are intended to be used as flowering potted plants in containers $\geq 15$-cm-diameter pots. Plant height for Maurine cultivars averaged 75 to $102 \mathrm{~cm}$ (Harbaugh and Scott, 1998) and Florida cultivars 28 to 
$35 \mathrm{~cm}$ (Harbaugh and Scott, 2001). Thus the UF Savanna cultivars were intermediate in height averaging 38 to $48 \mathrm{~cm}$. They have a spray-type flower display that is desirable if lisianthus are to be used as a pot plants making height control easier. Treatment with growth retardants is necessary for production of UF Savanna cultivars in $\leq 15$-cm-diameter pots (Harbaugh et al., 1998). Three to four plugs per 15-cm-diameter pot are recommended for optimal marketing display (Fig. 1).

\section{Availability}

Distribution of seed is through the Florida Foundation Seed Producers, P.O. Box 309, Greenwood, FL 332443.

\section{Literature Cited}

Fukuda, Y., K. Ohkawa, K. Kanematsu, and M. Korenga. 1994. Classification of Eustoma grandiflorum (Raf.) Shinn. cultivars on rosette characteristics based on the bolting ratios after a high temperature treatment. J. Jpn. Soc. Hort. Sci. 62:845-856.

Harbaugh, B.K. 1995. Flowering of Eustoma grandiflorum (Raf.) Shinn. cultivars influenced by photoperiod and temperature. HortScience 30:1375-1377.

Harbaugh, B.K., R.J. McGovern, and J.F. Price. 1998. Potted lisianthus: Secrets of success. Greenhouse Grower 16(1):42, 44, 46, 48, 50, 52.

Harbaugh, B.K., M.S. Roh, R.H. Lawson, and B. Pemberton. 1992. Rosetting of lisianthus cultivars exposed to high temperatures. HortScience 27:885-887.

Harbaugh, B.K. and J.W. Scott. 1996. 'Maurine Blue' lisianthus [Eustoma grandiflorum (Raf.) Shinn.]. HortScience 31:1055-1056.

Harbaugh, B.K. and J.W. Scott. 1998. Six heattolerant cultivars of lisianthus. HortScience 33:164-165.

Harbaugh, B.K. and J.W. Scott. 1999. 'Florida Pink' and 'Florida Light Blue'-Semi-dwarf heat-tolerant cultivars of lisianthus. HortScience 34:364-365.

Harbaugh, B.K. and J.W. Scott. 2001. 'Florida Silver'-A semi-dwarf heat-tolerant lisianthus. HortScience 36:988-989.

Harbaugh, B.K. and J.W. Scott. 2003. 'Maurine Twilight' and 'Maurine Daylight'-Heat-tolerant lisianthus with bicolored flowers. HortScience 38:131-132.

Harbaugh, B.K. and J.W. Scott. 2005 a. 'Maurine Dawn'-A heat-tolerant lisianthus with pink/white bicolored flowers. HortScience $40: 858-860$
Harbaugh, B.K. and J.W. Scott. 2005 b. 'Florida Blue Frill' and 'Florida Pink Frill'-Semi-dwarf heat-tolerant lisianthus with bicolored flowers. HortScience 40:861-863.

Harbaugh, B.K., J.W. Scott, and D.B. Rubino. 1996. 'Florida Blue' semi-dwarf lisianthus [Eustoma grandiflorum (Raf.) Shinn.]. HortScience 31:1057-1058.

Li, J., Y. Notsu, M. Ogawa, H. Ohno, and K. Ohkawa. 2002. Rosetting characteristics-based on classification of Eustoma grandiflorum (Raf.) Shinn. cultivars sown on different dates. (Japanese text with English abstract) Environ. Control Biol. 40:229-237.

Ohkawa, K., A. Kano, K. Kanematsu, and M. Korenaga. 1991. Effects of air temperature and time on rosette formation in seedlings of Eustoma grandiflorum (Raf.) Shinn. Scientia Hort. 48:171-176.

Ohkawa, K., T. Yoshizumi, M. Korenaga, and K. Kanematsu. 1994. Reversal of heat-induced rosetting in Eustoma grandiflorum with low temperatures. HortScience 29:165-166.

Pergola, G. 1992. The need for vernalizatin in Eustoma russellianum. Scientia Hort. 51:123-127.

Royal Horticultural Society. 1966. Royal Horticultural Society colour chart. Royal Hort. Soc., London. 